\title{
PENINGKATAN HASIL BELAJAR IPS MELALUI METODE TWO STAY TWO STRAY PADA SISWA KELAS V SDN CEMPAKA BARU 01 JAKARTA PUSAT
}

\author{
Friska Nur Prihati ${ }^{1}$, Ati Kusmawati² \\ ${ }^{1}$ Pendidikan Guru Sekolah Dasar, FKIP, Universitas Muhammadiyah Jakarta, \\ email: friska_nur_prihati@yahoo.com \\ ${ }^{2}$ Pendidikan Guru Sekolah Dasar, FKIP, Universitas Muhammadiyah Jakarta, \\ email: ati2051976@gmail.com
}

\begin{abstract}
This study entitled "Peningkatan Hasil Belajar IPS Melalui Metode Two Stay Two Stray pada Siswa Kelas V SDN Cempaka Baru 01 Jakarta Pusat”. The subject of this research is the grade $V$. This study departs from the background of the results of the study subjects are still low, IPS under KKM. So author moved to find the cause and try to improve the learning outcomes through learning methods two stay two stray (tsts). As for the purpose of this research is to improve the learning outcomes of students of class V SDN Cempaka Baru 01 on social science subjects.The method used is the class action Research with two cycles of hypothesis method with two stay two stray can improve the learning results of IPS on grade V in SDN Cempaka Baru 01. The results showed that the method can improve the learning results of tsts cognitive, affective and psychomotor the students in social science subjects. The results of the student learning experience an increase in classical and individually. This is due to the use of cooperative learning model of type two stay two stray has involved students learn actively and enhance their understanding of the material being taught. In Cycle I, students who complete of 44.83\%, cycle II of 93.10\%. While in the realm of affective in cycle I are classical space being in the category is good enough and in cycle II are in the category either. And in the realm of psychomotor, in classical average cycle I showed enough skilled category and on cycle II shows the category of skilled.
\end{abstract}

Keywords: two stay two stray, the results of the study, IPS.

\begin{abstract}
ABSTRAK
Penelitian ini berjudul "Peningkatan Hasil Belajar IPS Melalui Metode Two Stay Two Stray pada Siswa Kelas V SDN Cempaka Baru 01 Jakarta Pusat. Subjek penelitian ini adalah siswa kelas V. Penelitian ini berangkat dari latar belakang dari adanya hasil belajar mata pelajaran IPS yang masih rendah di bawah KKM. Sehingga penulis tergerak untuk mencari penyebabnya dan berusaha meningkatkan hasil belajar tersebut melalui metode pembelajaran two stay two stray (tsts). Adapun tujuan penelitian ini adalah untuk meningkatkan hasil belajar siswa kelas V SDN Cempaka Baru 01 pada mata pelajaran IPS. Metode yang digunakan adalah Penelitian Tindakan Kelas dengan dua siklus
\end{abstract}


dengan hipotesa metode two stay two stray dapat meningkatkan hasil belajar IPS pada siswa kelas V di SDN Cempaka Baru 01. Hasil penelitian menunjukkan bahwa metode tsts dapat meningkatkan hasil belajar kognitif, afektif serta psikomotorik siswa pada mata pelajaran IPS. Hasil belajar siswa mengalami peningkatan secara klasikal dan individual. Hal ini dikarenakan penggunaan model pembelajaran kooperatif tipe two stay two stray telah melibatkan siswa belajar secara aktif dan meningkatkan pemahaman mereka terhadap materi yang diajarkan. Pada Siklus I, siswa yang tuntas sebesar 44,83\%, siklus II sebesar 93,10\% .Sedangkan pada ranah afektif di siklus I secara klasikal berada di kategori cukup baik dan pada siklus II berada di kategori baik. Dan pada ranah psikomotorik, secara klasikal rata-rata di siklus I menunjukkan kategori cukup terampil dan pada siklus II menunjukkan kategori terampil.

Kata kunci: two stay two stray, hasil belajar, IPS.

\section{PENDAHULUAN}

Keberhasilan pendidikan dasar tidak terlepas oleh beberapa hal diantaranya guru, siswa, kurikulum, media, metode, evaluasi, sarana dan prasarana sehingga tujuan pendidikan nasional dapat terlaksana. Pembelajaran dapat dilakukan dengan bantuan pendidik (guru) atau ditemukan sendiri oleh individu (belajar secara otodidak). Berdasarkan pengamatan peneliti, salah satu pelajaran di sd adalah IPS. Tidak seperti pembelajaran ipa atau matematika yang banyak diminati oleh siswa karena sifat pasti dari pelajaran tersebut. ada kesan IPS tidak penting dan masyarakat menomor duakan IPS. Siswa merasa materi IPS terlalu banyak hafalan. Dan siswa merasa tidak sehebat ketika mereka mempelajari bahasa Inggris yang notabene diperlukan keterampilan bahasa Inggris tersebut di dunia kerja, dibandingkan ketika mempelajari IPS. Banyak siswa menganggap IPS merupakan mata pelajaran yang membosankan. Terlebih lagi, mata pelajaran IPS di sekolah dasar tidak dimasukkan sebagai mata pelajaran dalam Ujian Nasional. Ditambah lagi metode pembelajaran yang kurang tepat juga menimbulkan masalah dalam belajar sehingga hasil belajar siswa tidak memuaskan. Dalam hal ini diperlukan metode yang lebih inovatif, kreatif, efektif dan menyenangkan bagi siswa untuk menghidupkan suasana yang nyaman dan semangat siswa dalam belajar.

Berdasarkan pengalaman peneliti yang juga sebagai guru di sekolah dasar, kendala-kendala dalam pelaksanaan pembelajaran IPS pada siswa kelas V di SDN Cempaka Baru 01 juga terjadi. Hal tersebut terlihat pada penilaian harian mata pelajaran IPS pada tema 8 subtema 1 pembelajaran 3 dan 4 yang tidak memuaskan. Pada mata pelajaran IPS telah ditetapkan Kriteria Ketuntasan Minimal (KKM) yaitu 72. Namun pada nilai ulangan harian di Tema 8 
Lingkungan Sahabat Kita Subtema 2 Perubahan Lingkungan sebanyak 71\% nilai siswa masih berada di bawah KKM, dengan rata-rata kelas 53,33.

Mengacu pada latar belakang tersebut, peneliti ingin melakukan tindakan di dalam kelas. Peneliti mencoba mengadakan perbaikan pembelajaran untuk memperbaiki tingkat penguasaan siswa pada mata pelajaran IPS. Dalam hal ini metode pembelajaran yang biasa dilakukan dalam pembelajaran IPS akan dilakukan dengan metode pembelajaran yang menuntut dan menekankan pada keterlibatan siswa secara aktif sehingga mampu belajar mandiri dan meningkatkan kemampuan berpikir serta menyenangkan. Salah satu metode pembelajaran yang diterapkan adalah metode tipe Two Stay Two Stray yang termasuk dalam metode pembelajaran kooperatif. Berdasarkan hasil beberapa penelitian menunjukkan bahwa metode two stay two stray dapat meningkatkan hasil belajar. Salah satunya adalah penelitian yang dilakukan Siti Syamsiah dan Ganes Gunansyah (2014) terkait dengan Penerapan Model Pembelajaran Kooperatif Tipe Two Stay Two Stray Pada Mata Pelajaran IPS Untuk Meningkatkan Hasil Belajar Siswa Kelas IV A SDN Simomulyo 8 Surabaya menunjukkan pembelajaran dengan menerapkan model kooperatif tipe Two Stay Two Stray dapat meningkatkan aktivitas guru dan siswa, hasil belajar dan respon siswa kelas IV A SDN Sidomulyo 8 Surabaya. Oleh karena itu, diharapkan pembelajaran kooperatif tipe TSTS (two stay two stray) dapat menjadi alternatif penerapan strategi pembelajaran karena dirasa metdoe pembelajaran TSTS (two stay two stray) cocok meningkatkan hasil belajar IPS siswa di SDN Cempaka Baru 01.

Hasil belajar adalah pola-pola perbuatan, nilai-nilai, pengertianpengertian, sikap-sikap, apresiasi, dan keterampilan (Suprijono, 2015: 5). Menurut Bloom dalam Dedy Kustawan (2013: 15-16), ada tiga ranah atau domain hasil belajar, yaitu kognitif, afektif, dan psikomotor. Sedangkan pendidikan IPS menurut Jarolimek dalam Susanto (2013: 141) menyatakan bahwa pada dasarnya pendidikan IPS berhubungan erat dengan pengetahuan, keterampilan, sikap, dan nilai-nilai yang memungkinkan siswa berperan serta dalam kelompok masyarakat di mana ia tingga. Menurut Slavin dalam Isjoni (2010: 15) pembelajaran kooperatif adalah suatu model pembelajaran di mana siswa belajar dan bekerja dalam kelompok-kelompok kecil secara kolaboratif yang anggotanya 4-5 orang dengan struktur kelompok heterogen. Metode pembelajaran dua tinggal dua tamu (Two stay two stray) dikembangkan oleh Spencer Kagan (1992). Struktur two stay two stray memberikan kesempatan kepada kelompok untuk membagikan hasil dan informasi dengan kelompok lain (Lie, 2008: 61). Pada metode pembelajaran two stay two stray ini siswa bukan hanya belajar dan menerima apa yang disajikan materi yang di sampaikan oleh guru pada saat pembelajaran, melainkan siswa bisa juga belajar dari siswa 
lainnya. Metode pembelajaran two stay two stray adalah metode pembelajaran kooperatif dimana siswa secara berkelompok saling berdiskusi dan membagi tugas serta saling aktif bertukar informasi dengan kelompok lainnya.

\section{METODE PENELITIAN}

Penelitian ini dilaksanakan di SDN Cempaka Baru 01 Jakarta Pusat. Faktor faktor yang diteliti dalam penelitian ini adalah hasil belajar siswa yang ditentukan dengan beberapa indikator yaitu skor tes kognitif, skor tes afektif dan psikomotorik. Penelitian yang dilakukan adalah penelitian tindakan kelas yang dilakukan bersiklus. Setiap siklus terdapat 4 tahap yaitu perencanaan (planning), pelaksanaan atau tindakan (acting), observasi (observasing), dan refleksi (reflecting). Penelitian ini akan dilakukan dalam 2 siklus. Setiap siklus dilakukan dalam 4 jam pelajaran.

Sumber data dalam penelitian ini adalah siswa kelas VB SDN Cempaka Baru 01 Tahun pelajaran 2018/2019 yang berjumlan 29 siswa. Penelitian dilaksanakan pada semester II tahun pelajaran 2018/2019 tepatnya pada bulan Maret-April 2019.

Data yang diperoleh adalah data hasil belajar yang diukur dengan tes tertulis yang dilaksanakan disetiap siklus. Pada penelitian ini dilaksanakan 2 siklus. Selain itu data juga diperoleh dari lembar observasi untuk hasil belajar ranah afektif dan psikomotorik siswa. teknik pengumpulan data yang dilakukan adalah observasi, dokumentasi, dan tes hasil belajar. Teknik analisis data, peneliti menggunakan perolehan data dari hasil belajar siswa dan lembar observasi selama pelaksanaan siklus I dan II. Hasil belajar dianalisis dengan membuat ratarata nilai tes formatif yang kemudian dibuat persentasenya.

\section{HASIL DAN PEMBAHASAN}

Hasil belajar kognitif diukur dari perolehan nilai pada soal tes kognitif yang berupa soal pilihan ganda yang berjumlah 10 dan isian yang berjumlah 10 . Berdasarkan tindakan yang telah dilaksanakan pada siklus I dan II dengan menggunakan metode two stay two stray untuk meningkatkan hasil belajar IPS pada siswa kelas V B SDN Cempaka Baru 01 untuk pada Tema Lingkungan Sahabat Kita Subtema Usaha Pelestarian Lingkungan dapat dikatakan berhasil karena menurut pengamatan dan refleksi yang telah dilakukan, siswa terlibat langsung dalam proses pembelajaran, siswa dibimbing secara berkelompok mencari jawaban dan memperoleh pemahaman dalam belajar sehingga siswa lebih aktif dalam belajar. Hasil belajar tersebut meliputi ranah kognitif, afektif dan psikomotorik. Hal ini sejalan dengan teori Bloom dalam Dedy Kustawan (2013: 15-16), ada tiga ranah atau domain hasil belajar, yaitu kognitif, afektif, dan psikomotor. Ranah kognitif, yang berisi perilaku-perilaku yang menekankan 
aspek intelektual, seperti pengetahuan, pemahamaan, dan penerapan. Ranah afektif berisi perilaku-perilaku yang menekankan aspek perasaan dan emosi, seperti minat, sikap, apresiasi, dan cara penyesuaian diri. Dan ranah psikomotorik berisi perilaku-perilaku yang menekankan aspek keterampilan motorik seperti tulisan tangan, mengetik, berenang, dan mengoprasikan mesin.

Dalam tahap pengamatan baik di siklus I ataupun siklus II, pembelajaran dengan penggunaan metode two stay two stray ini memperlihatkan tingkat keaktifan siswa dalam kerja sama, mendengarkan siswa lain dan juga tanggung jawab. Dalam metode ini siswa tidak diharuskan harus duduk diam di kelas, tetapi mengharuskan siswa bergerak dari satu kelompok ke kelompok yang lain. Oleh sebab itu metode ini terbukti dan sesuai dengan tulisan Nursidik Kurniawan (2011) tentang karakteristik anak SD yaitu senang bermain, senang bergerak (orang dewasa dapat duduk berjam-jam, sedangkan anak SD dapat duduk dengan tenang paling lama sekitar 30 menit), senang bekerja dalam kelompok dan senang merasakan atau melakukan/memperagakan sesuatu secara langsung. Hal ini juga diperkuat dengan Salah satu teori belajar konstruktivisme Vygotsky yang menekankan pada aspek sosiokultural dalam pembelajaran. Menurut Vygotsky siswa membentuk pengetahuan sebagai hasil dari pikiran dan kegiatan siswa sendiri melalui interaksi dengan lingkungan karena Vygotsky percaya bahwa interaksi sosial dengan orang yang lebih dewasa atau teman yang lebih cakap akan memacu terbentuknya ide baru dan memperkaya pengetahuan intelektual siswa.

Dalam setiap tahap siklus nya, peningkatan hasil belajar menggunakan metode two stay two stray meningkat secara bertahap. Jika dituangkan dalam bentuk tabel dan diagram adalah seperti di bawah ini.

Tabel 1.

Perbandingan Nilai Rata-Rata Siswa Pra Siklus, Siklus I dan Siklus II

\begin{tabular}{|l|c|c|c|}
\hline \multirow{2}{*}{ Hasil Belajar } & \multicolumn{3}{|c|}{ Tahapan } \\
\cline { 2 - 4 } & Pra Siklus & Siklus I & Siklus II \\
\hline Kognitif & 53,10 & 67,93 & 77,07 \\
\hline Afektif & & 58,00 & 80,00 \\
\hline Psikomotorik & & 60,00 & 77,00 \\
\hline
\end{tabular}




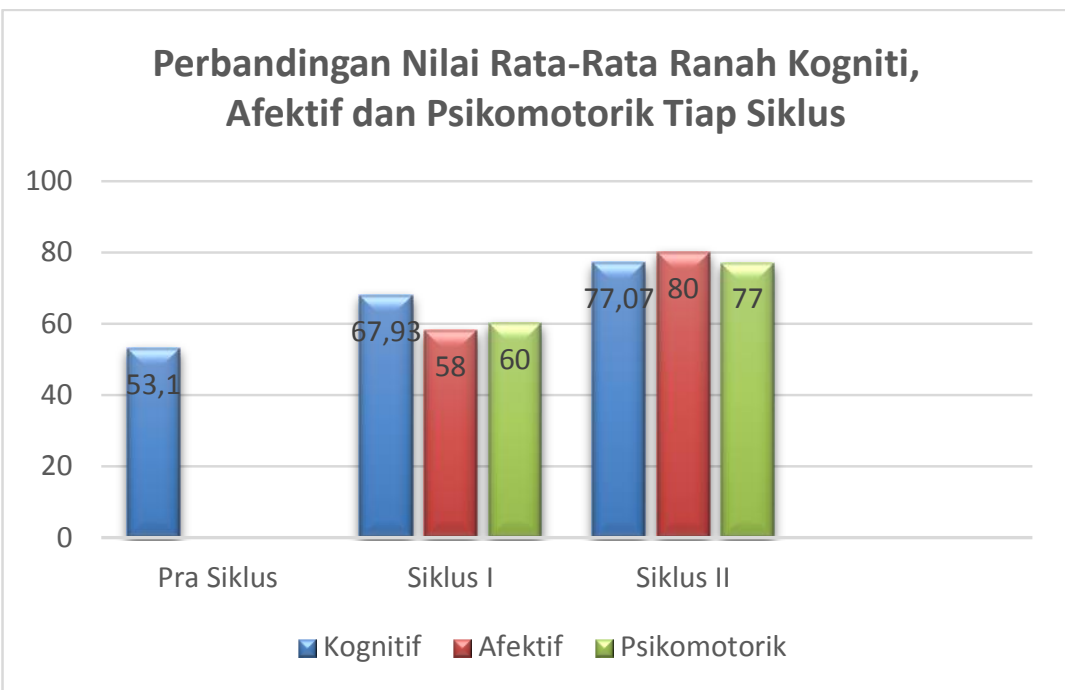

Gambar 1. Diagram perbandingan nilai rata-rata ranah kognitif, afektif, dan psikomotorik tiap siklus

Adapun ketuntasan hasil belajar tiap siklus adlah sebagai berikut:

Tabel 2.

Ketuntasan Hasil belajar Tiap Siklus

\begin{tabular}{|l|c|c|c|c|c|c|}
\hline \multirow{3}{*}{ Hasil Belajar } & \multicolumn{6}{|c|}{ Tahapan } \\
\cline { 2 - 7 } & \multicolumn{2}{|c|}{ Pra Siklus } & \multicolumn{2}{c|}{ Siklus I } & \multicolumn{2}{c|}{ Siklus II } \\
\cline { 2 - 7 } & Tuntas & $\begin{array}{c}\text { Belum } \\
\text { Tuntas }\end{array}$ & Tuntas & $\begin{array}{c}\text { Belum } \\
\text { Tuntas }\end{array}$ & Tuntas & $\begin{array}{c}\text { Belum } \\
\text { Tuntas }\end{array}$ \\
\hline Kognitif & 4 & 25 & 13 & 16 & 27 & 2 \\
\hline Afektif & & & 7 & 22 & 28 & 1 \\
\hline Psikomotorik & & & 11 & 18 & 28 & 1 \\
\hline
\end{tabular}


Friska Nur Prihati, Ati Kusmawati : Peningkatan Hasil Belajar IPS Melalui Metode Two Stay Two Stray pada Siswa Kelas V SDN Cempaka Baru 01 Jakarta Pusat

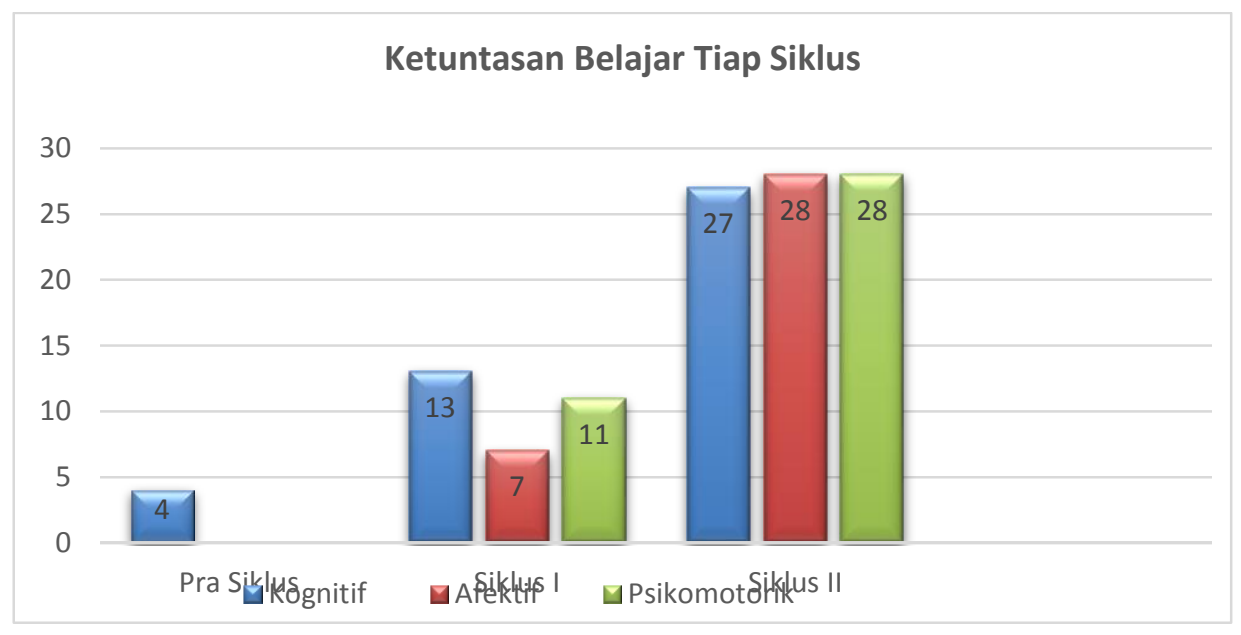

Gambar 2. Diagram Ketuntasan belajar tiap siklus

Jika digambarkan tahapan-tahapan siklus dalam penelitian dengan menggunakan metode two stay two stray ini adalah sebagai berikut:

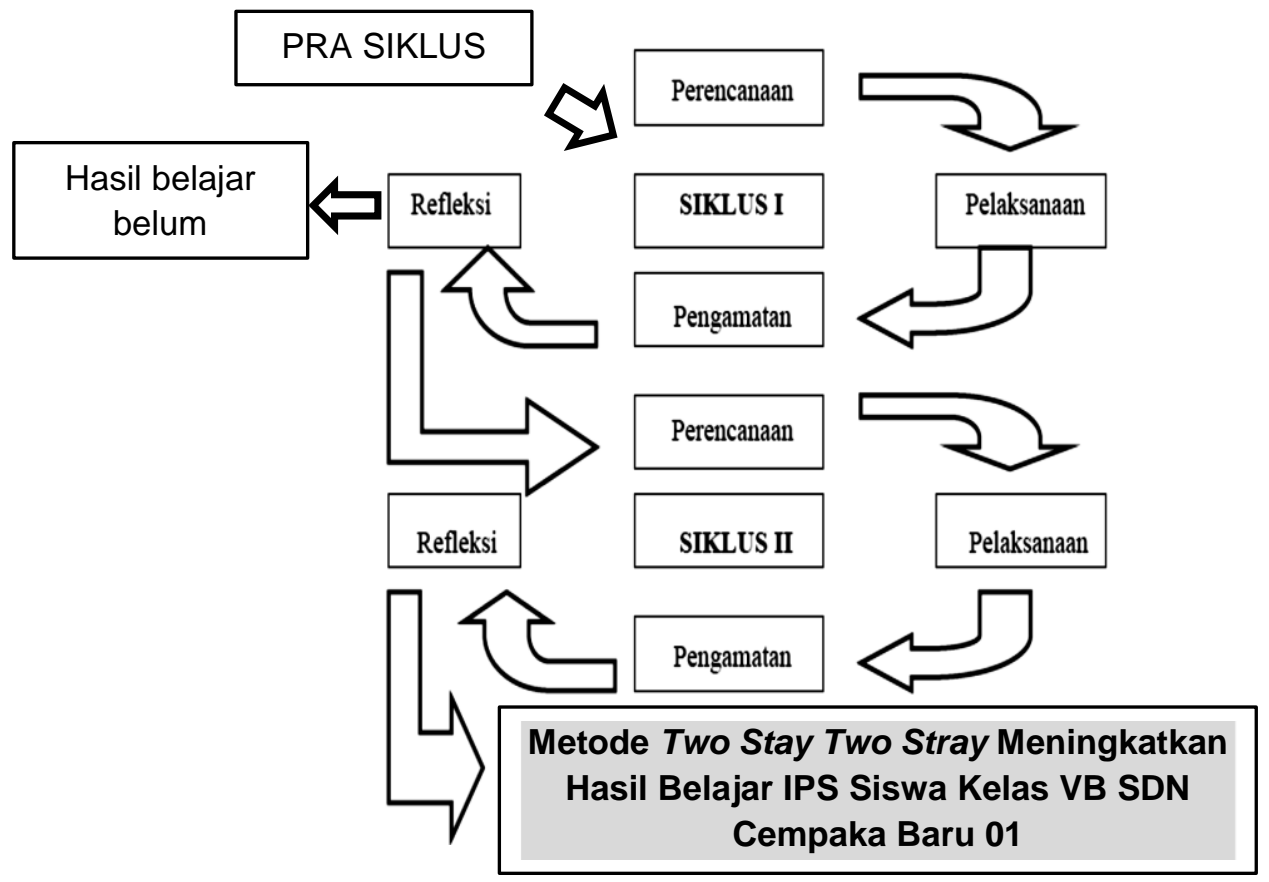

Gambar 3. Siklus PTK dengan metode two stay two stray 
Akhirnya dapat ditegaskan bahwa terdapat peningkatan hasil belajar IPS melalui metode two stay two stray pada siswa kelas V B SDN Cempaka Baru 01 Jakarta Pusat. Dan pembelajaran dengan menggunakan metode two stay two stray memberikan pengaruh yang sangat besar terhadap hasil belajar baik dalam ranah kognitif, afektif dan psikomotorik.

\section{PENUTUP}

Berdasarkan hasil penelitian dapat disimpulkan bahwa pembelajaran IPS dengan menggunakan metode two stay two stray (tsts) dapat meningkatkan hasil belajar. Metode ini melibatkan aktivitas seluruh siswa tanpa harus ada perbedaan status. Dengan metode ini siswa juga bisa bergerak sesuai dengan karakter anak SD yang biasanya lebih cepat jenuh apabila harus belajar dengan duduk diam saja. Dengan metodde tsts siswa mendapat kesempatan untuk berrgerak, berjalan-jalan di kelas bahkan bisa saling berkomunikasi dengan teman-temannya

Berdasarkan hasil penelitian dapat disimpulkan bahwa pembelajaran IPS dengan menggunakan metode two stay two stray ( $t s t s$ ) dapat meningkatkan hasil belajar. Metode ini melibatkan aktivitas seluruh siswa tanpa harus ada perbedaan status. Dengan metode ini siswa juga bisa bergerak sesuai dengan karakter anak SD yang biasanya lebih cepat jenuh apabila harus belajar dengan duduk diam saja. Dengan metodde tsts siswa mendapat kesempatan untuk berrgerak, berjalan-jalan di kelas bahkan bisa saling berkomunikasi dengan teman-temannya.

Aktivitas belajar dalam metode tsts memungkinkan setiap individu selalu berusaha untuk bisa menyelesaikan tugas yang diberikan oleh guru di samping itu menumbuhkan rasa kerja sama, mendengarkan orang lain, dan tanggung jawab. Selain itu metode ini juga dapat menumbuhkan kreativitas siswa, melatih keterampilan bertanya untuk mencari informasi, keterampilan menjelaskan informasi dan juga keteramilan berbicara di depan kelas. Metode ini dapat digunakan untuk memaksimalkan kegiatan pembelajaran sehingga terjadi peningkatan hasil belajar siswa.

Diharakan Bagi Kepala Sekolah harus lebih memotivasi guru dengan mengadakan pelatihan dan fasilitas pembelajaran dengan menggunakan metodemetode baru dan bervariasi salah satunya dengan menggunakan metode pembelajaran two stay two stray yang mengedepankan belajar kelompok. Dan untuk guru harus membuat siswa aktif dan termotivasi belajar agar siswa semangat dalam mengikuti kegiatan pembelajaran. Disamping itu guru hendaknya bersifat sebagai fasilitator siswa yang berfungsi memfasilitasi siswa agar siswa mandiri dan percaya diri dalam memecahkan masalahnya tanpa tergantung yang lain. Dan untuk siswa bahwa dengan menggunakan metode two stay two stray 
proses belajar menjadi lebih menyenangkan dan dapat meningkatkan hasil belajar siswa dan keaktifan siswa khususnya dalam pembelajaran IPS. Untuk tercapainya peningkatan hasil belajar, sebaiknya siswa dapat lebih berani dan percaya diri dalam berbicara ataupun dalam bersosialisasi dengan teman-teman di kelas.

\section{DAFTAR PUSTAKA}

Isjoni. 2010. Pembelajaran Kooperatif Meningkatkan Kecerdasan Komunikasi Antar Peserta Didik. Yogyakarta : Pustaka Pelajar.

Kurniawan, Nursidik. 2011. Diakses dari https://dgirlss.wordpress.com /karakteristik-dan-kebutuhan-pendidikan-anak-usia-sekolah-dasar-olehnursidik-kurniawan-a-ma-pd-sd/ pada tanggal 14 September 2018.

Kustawan, Dedy. 2013. Analisis Hasil Belajar, Program Perbaikan dan Pengayaan Peserta Didik Berkebutuhan Khusus. Jakarta: Luxima.

Lie, Anita. 2008. Cooperative Learning, Jakarta: PT. Grasindo.

Suprijono, Agus. 2015. Cooperative Learning Teori dan Aplikasi PAIKEM. Yogyakarta: Pustaka Pelajar.

Susanto, Ahmad. 2013. Teori Belajar dan Pembelajaran di Sekolah Dasar. Jakarta: Kencana.

Syamsiah, Siti dan Gunansyah, Ganes. 2014. "Penerapan Model Pembelajaran Kooperatif Tipe Two Stay Two Stray Pada Mata Pelajaran IPS Untuk Meningkatkan Hasil Belajar Siswa Kelas IV A SDN Simomulyo 8 Surabaya”. JPGSD 2(1). 